\title{
PRINCIPIOLOGIA DO ECA NO CASO BEBÊ JONATAS E A ACUSAÇÃO DE CRIME PATERNAL: representações sociojurídicas sobre direito da criança e o dever dos pais
}

\author{
PRINCIPIO DEL ECA EN EL CASO DEL BEBÉ JONATAS Y LA ACUSACIÓN DE \\ DELITO PATERNO: representaciones socio-legales sobre el derecho de los \\ hijos y el deber parental
}

\section{PRINCIPLES OF ECA IN THE JONATAS BABY CASE AND THE CHARGE OF PARENTAL CRIME: socio-legal representations}

\author{
Ricardo Cortez Lopes ${ }^{1}$ \\ https://orcid.org/0000-0003-0808-7203
}

\begin{abstract}
Resumo
O caso do bebê Jonatas, criança catarinense portadora de uma doença extremamente agressiva, mobilizou um bom número de doações financeiras, sejam elas em espécie, sejam em gênero. A controvérsia pública se deu por conta de algumas atitudes dos pais da criança após as doações, em que foram adquiridos bens e realizadas viagens. O presente artigo aborda a controvérsia para explicar o modo como a justiça brasileira lidou com o caso: ao não conseguir enquadrar o casal juridicamente através do ECA, tentou proteger a criança e aplacar a condenação pública utilizando o código civil e o código penal, na busca da equidade. A conclusão do estudo é que o ECA tornou válido o direito da criança e o código penal foi mobilizado para lidar com os pais.
\end{abstract}

Palavras-Chave: Direito da criança. Criança com deficiência. Bebê Jonatas. ECA. Equidade.

\section{Resumen}

El caso del bebé Jonatas, un niño de Santa Catarina con una enfermedad extremadamente agresiva, movilizó un buen número de donaciones económicas, sean en especie o en especie. La polémica pública se debió a algunas actitudes de los padres del niño tras las donaciones, en las que se compraban bienes y se realizaban viajes. Este artículo aborda la polémica para explicar la forma en que la justicia brasileña manejó el caso: al no enmarcar legalmente a la pareja a través de ECA, intentó proteger al niño y aplacar la condena pública utilizando el código civil y el código penal, en la búsqueda. de equidad. La conclusión del estudio es que la ECA hizo válido el derecho del niño y se movilizó el código penal para tratar con los padres.

Palabras clave: derecho del niño; niño discapacitado; bebé Jonatas; ECA; equidad;

\section{Abstract}

\footnotetext{
1 Doutor em Sociologia (UFRGS). Atua no Núcleo Pedagógico da Faculdade IBCMED como Analista Educacional. E-mail: rshicardo@hotmail.com
}

\section{Como referenciar este artigo:}

LOPES, R. C. Principiologia do ECA no caso bebê Jonatas e a acusação de crime paternal: representações sociojurídicas sobre direito da criança e o dever dos pais. Revista Pedagógica, v. 23, p. 1-28, 2021. DOI http://dx.doi.org/10.22196/rp.v22io.5665 
The case of baby Jonatas, a child from Santa Catarina with an extremely aggressive disease, mobilized a good number of financial donations, be they in kind or in kind. The public controversy was due to some attitudes of the child's parents after the donations, in which goods were purchased and trips were made. This article addresses the controversy to explain the way in which Brazilian justice handled the case: by failing to legally frame the couple through ECA, it tried to protect the child and placate public condemnation using the civil code and the criminal code, in the search of equity. The conclusion of the study is that the ECA made the child's right valid and the penal code was mobilized to deal with the parents.

Keywords: child's right; children with disabilities; Baby Jonatas; ECA; equity.

\section{INTRODUÇÃO}

O caso do bebê Jonatas, criança catarinense diagnosticada com a doença Atrofia Muscular Espinhal (AME), gerou muita repercussão e aderência nacional e internacional. Viagens e bens adquiridos após o lançamento oficial da campanha levantaram a suspeita em alguns internautas de que os pais do menino estariam usando o dinheiro obtido para aquisições não relacionadas diretamente com a causa. Na sequência temporal de um clamor público, as instituições de direito começaram a agir e, para isso, precisaram legitimar suas ações em textos, cujas consequências jurídicas foram informadas pela imprensa. Curiosamente, o Estatuto da Criança e do Adolescente (ECA) não foi um deles, mesmo que o envolvido seja considerado pela lei como uma criança ao se levar em conta a sua idade.

Nosso intuito é realizar uma sociologia da resposta da Justiça Brasileira a essa crise através de dois eixos: (1) a indignação de conterrâneos e (2) o modo como o casal foi enquadrado pela justiça segundo legislações divulgadas na mídia. O segundo mobilizou o primeiro e pareceu criar a necessidade de se buscar a equidade, uma vez que nenhuma normativa de algum código em separado dava conta da complexidade do caso. Tal paradoxo da leitura decorreu por se tratar de doação, procedimento que conta com especificidades legais.

As implicações dessa discussão para o campo da educação são muitas. A começar na construção do currículo, pois há uma concepção teórica do que é o aluno que se embasa, também, na concepção moral do que é o aluno e do que ele precisa para ser feliz, o que implica nas discussões promovidas pela pedagogia de Durkheim na educação moral (2017). 
Em seguida, a discussão de direitos sociais implica, também, no direito da educação (DUARTE, 2007, p.694), uma vez que foi a efetivação do direito à saúde que mobilizou os doadores. Por fim, essa pesquisa permite problematizar o ECA em si mesmo, que efetiva o acesso ao direito e educação para crianças em vulnerabilidade social.

Esse texto está organizado da seguinte maneira: primeiramente, apresentaremos o caso; em seguida, estudaremos a sua repercussão social (com o seu referencial teórico respectivo) e, posteriormente, apreciaremos a sua repercussão jurídica através de fontes secundárias. Não serão analisados todos os argumentos jurídicos (que seriam as fontes primárias) por conta do segredo de justiça; porém, podemos consultar a legislação por meio das respostas que foram dadas através de notícias do caso, e a partir delas comparar aquilo que foi executado com a legislação original. Por fim, vamos articular todos esses dados e produzir uma análise mais ampla da situação, com o objetivo de retratar uma situação em que a sociedade "adentra" no direito.

\section{CASO}

A sequência de acontecimentos teve início com o diagnóstico de AME da criança catarinense Jonatas Henrique Openkoski, em exame realizado no começo do ano 2017 no seu município de residência. Essa patologia crônica possui o nome técnico de síndrome de Werdnig Hoffmamm, “doença rara e degenerativa que afeta o sistema nervoso e provoca a redução de funções motoras. O menino tem movimentos limitados, alimenta-se por sonda e respira com ajuda de aparelhos" (CARNEIRO, 2018, s/p). Essa doença acarreta, quase sempre, a morte do paciente: "Sua única esperança de sobreviver à doença era o medicamento Spinraza (as seis doses iniciais custavam perto de 3 milhões de reais na época (a aprovação no Brasil, tempos depois, ajudou a baixar o custo)" (BASSETE, 2018, s/p).

Em março do mesmo ano foi criada, na rede social Facebook, a campanha "Ame Jonatas", cuja arrecadação serviria para custear o tratamento da criança, que "incluía a compra de doses do Spinraza - medicamento fabricado apenas nos Estados Unidos e que vem trazendo resultados positivos para a reversão de alguns dos sintomas da atrofia" (CARNEIRO, 2018, s/p). Essa seria uma campanha de arrecadação normal entre outras realizadas na rede social, não fosse a proporção inesperada que tomou: para ela doaram 
artistas e mesmo brasileiros residentes nos Estados Unidos (CARNEIRO, 2018). Ao total, foram arrecadados 4 milhões de reais (BASSETE, 2018). Como podemos observar, por algum motivo muito forte - que foi intensa na mesma medida na repulsa - a campanha criou uma rede de colaboração imensa. O apoio mais geral parece ter se revertido quando algumas qualidades de gastos dos responsáveis legais começaram a ser contestadas, aliadas a acusações de uma alegada falta de transparência (CARNEIRO, 2018).

Cumpre notar que o Ministério Público (MP) de Santa Catarina acabou se responsabilizando pela investigação do caso, averiguando os seguintes pontos: "a demora na importação do remédio e quanto foi gasto para adquiri-lo, a mudança da família para uma casa maior, além da viagem a Noronha e a compra do carro" (CARNEIRO, 2018). A instância foi acionada por usuários que observaram fotos nas redes sociais e o que se seguiu cronologicamente foi a resposta direta da justiça: "Em audiência judicial, foi acordado que até 31 de outubro de 2017 o casal prestaria contas dos recursos arrecadados e despesas feitas, o que não ocorreu, segundo o Ministério Público" (MARINHO, 2018). Na iminência da não prestação de conta, a Justiça bloqueou os valores arrecadados pela campanha por determinação do mesmo MP (MARINHO, 2018).

Portanto, o segredo de justiça impossibilita o acesso aos autos e os processos, porém podemos perceber as reações jurídicas por meio dos relatos da imprensa, que descrevem os passos do acontecimento. Segundo registros consta que foi determinada a apreensão de alguns itens: “[...] um carro avaliado em 140.000 reais e uma TV de 50 polegadas avaliada em 6000 reais, todos adquiridos depois da campanha de arrecadação. Parte dos objetos seria leiloada para arrecadar fundos" (BASSETE, 2018, s/p). Entretanto, ainda haveria muito mais bens, segundo relato de uma autoridade policial: carro, moto, objetos de luxo e objetos doados (BASSETE, 2018).

Após essas determinações, uma delegada solicitou a prisão preventiva do pai do bebê por conta de suas afirmações, as de que o judiciário estaria atrapalhando a família nos cuidados com o menino. Para a autoridade, o pai estaria "se aproveitando da boa fé das pessoas e da imagem da criança, que sensibiliza, para poder obter vantagem ilícita" (G1 SC, 2018, s/p).

Em 2018 a justiça criou uma conta judicial para a campanha e liberou 30 mil reais para o gasto exclusivo com o tratamento. Porém, após as irregularidades nas prestações 
de conta já mencionadas, foi aberto novo inquérito e não houve mais repasse de recursos, com a proibição do início de novas campanhas (FLORÊNCIO, 2019). As informações dão conta, também, que o menino seguiu em tratamento e chegou a sofrer um ataque cardíaco, do qual se recuperou. Atualmente, o carro, que seria leiloado, foi liberado novamente para o uso da família (ABATTI, 2020).

Em síntese, podemos perceber que os supostos doadores começaram a denunciar o caso para o MP, que solicitou o bloqueio dos bens. A partir daí, a justiça investigou e declarou a prisão dos pais. Será interessante, a partir de agora, descortinar essas dimensões, a começar pela questão da apreciação moral das atitudes do casal.

\section{REPERCUSSÃO PÚBLICA: REFERENCIAL TEÓRICO}

A miríade de concepções expostas nas falas coletadas apontou para, no mínimo, uma articulação conceitual. É claro que não estamos realizando um conhecimento do zeitgeist, ou coisa que o valha, porque nosso interesse não é conduzir um estudo histórico ou "reconstitutivo" de uma época. Nosso objetivo é captar parte das representações sociais envolvidas e aplicadas no julgamento dos acontecimentos, mas elas só podem ser compreendidas se a estudarmos a partir de outros elementos que estão tensionando apreciações morais. Dessa maneira, fica evidente que o julgamento realizado por essa representação se baseia numa leitura moderna que envolve mecanismos de dádiva, cuja não retribuição leva ao bode expiatório, estrutura que se mescla com a concepção brasileira sobre criança inocente, relacionada ao bom selvagem.

Do ponto de vista sociológico, a modernidade foi um projeto de mundo que se mostrou bastante ambicioso: pretendia superar todas as limitações dos pensamentos nãomodernos e produzir a felicidade generalizada através da autonomia moral de indivíduos iguais e solidários entre si. Tal projeto otimista mobilizou muitos indivíduos, instituições e nações: "O período [...] costuma ser chamado pelos historiadores de "belle époque". Como o nome indica, este foi um período de progresso e otimismo, marcado por grandes invenções (eletricidade, avião, submarino, cinema, automóveis, etc.)" (SELL, 2017, p.28). Mas ainda havia outros motivos para essa sensação de um futuro brilhante (PETRY, 2015). 
Esse conjunto de pressuposições que embasaram a espera de um porvir favorável encontrou discordâncias, sugestões de reformulação, além de enfrentar acontecimentos que as contrariaram. A bomba atômica de Hiroshima e o holocausto (ALMOND; VERBA, 1970), por exemplo, criaram destruição em larga escala, ambos possibilitados pelo mesmo progresso técnico e, a partir daí, houve também desistências desse projeto como um todo. Assim, o pessimismo com a modernidade pode provir de muitas vias: (a) pré-modernidade, (b) anti-modernidade e (c) decepção com o projeto moderno. No caso, o pessimismo parece recair na via (c), que sofre uma falácia da composição: a humanidade como um todo passa a ser partícipe desse ranço.

Essa aparelhagem moral, portanto, ajuda a contextualizar, mas não esgota a questão. Quando se realiza um julgamento moral, um indivíduo e sua ação vão ser lidos nos termos de sua atitude corresponder a essa solidariedade do otimismo moderno: quanto mais ele pensa no seu bem pessoal, menos “civilizado" ele é e menos digno de apreciação moral positiva acaba sendo. Essa é a chamada noção de reciprocidade:

[...] a noção de dádiva baseia-se em quatro afirmações: a primeira, que a dádiva é o fenômeno empírico que permite estudar a fabricação elementar da solidariedade social, tanto na sociedade moderna como em todas as outras; a segunda, que a dádiva moderna se realiza principalmente no espaço da sociabilidade primária, o que remete à vida afetiva, à vizinhança, na qual se desenvolvem as obrigações de dar, receber e retribuir; a terceira, que o espaço da sociabilidade secundária, regida pelas normas burocráticas e mercantis da eficiência e do utilitarismo, mas apoiada nas práticas da dádiva da sociabilidade primária, abre a dimensão política da dádiva, segundo a qual a solidariedade se ancora no mundo das associações e do voluntariado. A quarta, por fim, é que, na sociedade moderna, produz-se uma dádiva nova, a "dádiva a estranhos", que permite escapar do círculo fechado das relações interpessoais (STEINER, 2017, p. 23)

Assim, quando uma atitude é condenada moralmente, a sanção pode ser direta ou ocorrer através do bode expiatório. A sanção direta implica em prejuízo direcionado ao transgressor, porém o mecanismo do bode expiatório serve para "expulsar" o membro do grupo e preservar os valores compartilhados:

O mito substitui a violência recíproca, espalhada em toda parte, pela formidável transgressão de um indivíduo único [...] Na crise sacrificial, todos os antagonistas acreditam estar separados por uma diferença enorme. Na realidade, todas as diferenças desaparecem pouco a pouco. Em toda parte há o mesmo desejo, o 


\section{REVISTA}

mesmo ódio, a mesma estratégia, a mesma ilusão de diferença enorme na uniformidade mais completa. (GIRARD, 1990, p.100 e 107)

É de se ressaltar que o bode expiatório parece fazer um bem ao grupo em ao menos um sentido, pois evita que o grupo precise repensar suas atitudes e valores: "[...] então, o grupo estrutura-se como grupo conspirador para se opor à mudança, já que esta é vivenciada como um "enlouquecer", como um aumento do desamparo, da insegurança e da incerteza grupal" (PICHON-RIVIÈRI, 2005, p.144). Assim, a crise sacrificial reforça o normal através do que considera patológico e o grupo mantém uma segurança ontológica, pois a transgressão é ligada diretamente à personalidade transgressora do indivíduo. Porém, como veremos adiante, os dados parecem mostrar que estamos lidando com sujeitos que vivem em grupo (no caso, a sociedade) sem concordar com os seus valores básicos (o que Durkheim chamaria de representações coletivas).

Diferentemente das sociedades pré-modernas, nas sociedades globais o indivíduo pertence a muitos grupos simultaneamente, além de ser um cidadão formal em seu estado nacional (ROSATI; WEISS, 2015). Assim, vários grupos são geridos por diferentes mecanismos e o indivíduo constrói sua identidade nesses entrecruzamentos, ou seja, a mesma ação pode ser julgada por diferentes grupos, com diferentes possibilidades de bode expiatório, às vezes bodes expiatórios que se contradizem entre si.

Como já relatado, um dos valores morais mais básicos da modernidade é o da igualdade: "a tríplice obrigação do dar, receber e retribuir" (MARTINS, 2005, p.46). É nesta dimensão que entra a dádiva: ela é a oportunidade de se exercer a solidariedade, mas deve haver o reforço dos valores supraindividuais. Por esse motivo, a dádiva é um simulacro do projeto moderno para toda a humanidade: "A partir do ideal de igualdade e reciprocidade presente nas relações modernas, podemos pensar a forte incidência da definição de infidelidade como desrespeito ao outro. A traição é a mentira, o rompimento da confiança" (WEID, 2004, p.4). O esperado como correto é o altruísmo, caracterizado como um fim em si mesmo e como a capacidade de restituir um favor prestado (DE ABREU, 1983).

A unidade de análise do estudo são as representações sociais. Estas são fragmentos simbólicos que buscam copiar seus referentes e que são compartilhados por grupos para significar e ressignificar o mundo ao seu redor (MOSCOVICl, 2009). Nesse caso, as 
representações sociais emitem julgamentos sobre pessoas e acontecimentos, com base nas quais consideram como a normalidade.

Por fim, a última questão teórica é a representação de criança. Casos como o da menina Isabella (LOPES; DE AGUIAR, 2017), além da apreciação dos casos de violência contra as crianças João Hélio (em 2007), Eloá e Bernardo (2014), causadores de um furor coletivo em suas respectivas épocas: todos são indicativos de uma leitura moral sobre as crianças. E, mais especificamente, da criança como um ser inocente:

\begin{abstract}
A imagem da criança "inocente" fundamenta-se no pensamento de Rousseau, segundo o qual o homem é naturalmente bom e tudo aquilo que sob o olhar do adulto pode ser considerado como maldade deve ser compreendido como resultado da ação dos mais velhos [...] Aquilo que eventualmente pode ser considerado como maldade é construído nas crianças por meio do tratamento que Ihes dispendemos (TEBET, 2013, p.31)
\end{abstract}

É preciso ressaltar que a criança é um dos repositórios dessa pureza, que também parece ser atribuída aos animais, por exemplo (vide repercussão de maus tratos dirigidos a eles em mídias sociais e na mídia mainstream). A sociedade, nessa perspectiva, é corrompedora do que está intocado e natural e, portanto, era "puro". Em síntese: romper com a reciprocidade gera um transtorno, o que se agrava com o envolvimento da criança, o último bastião da pureza - talvez daí tenha se gerado o amplo envolvimento com as doações para o bebê. Todavia, o pessimismo como ferramenta de apreciação moral faz com que o fato seja lido por um ângulo diferente: ele confirma essa corrupção e a criança (justamente aquilo que poderia resistir a essa corrupção), é envolvida diretamente nela a partir de seus pais, considerados gananciosos. Assim, o bode expiatório é a moralidade brasileira (e em alguns casos a humana), que não deveria ser assim, que deveria respeitar os ditames otimistas. $O$ bode, portanto, se inverte: de individual para manter o social, vira social para permitir que o indivíduo se "salve" da sociedade. É como se esta última fosse um oceano de devassidão prestes a afundar "ilhas de pureza".

\title{
3.1 Representações sociais elencadas
}




\section{REVISTA}

Revista do Programa de Pós-Graduação em Educação da Unochapecó ISSN 1984-1566 (on-line) ISSN 1415-8175 (impressa)

Os comentários serão o indicador das representações envolvidas no julgamento moral. Vamos observar que algumas representações reverberam nessas declarações e nosso objetivo é o de proceder essa identificação no decorrer da análise. Preliminarmente, podemos alertar para a existência de três delas, conforme segue na tabela 1:

Tabela 1: lista de representações de crianças e suas descrições

\begin{tabular}{|c|l|}
\hline $\begin{array}{c}\text { Lista de representações sobre } \\
\text { crianças }\end{array}$ & \multicolumn{1}{c|}{ Descrição } \\
\hline Centro & $\begin{array}{l}\text { Todos os esforços dos pais devem se direcionar para o bem-estar da } \\
\text { criança, mesmo que isso redunde em sofrimento direto para ambos. }\end{array}$ \\
\hline Paralelo & $\begin{array}{l}\text { O bem-estar da criança é importante, mas é preciso cuidar também } \\
\text { do bem dos próprios pais em paralelo. }\end{array}$ \\
\hline Egoísta & $\begin{array}{l}\text { Os pais podem pensar em si mesmos, independentemente dos } \\
\text { filhos, pois estes últimos irão se beneficiar do egoísmo dos pais. }\end{array}$ \\
\hline
\end{tabular}

Fonte: autoria própria (2019)

O texto, daqui em diante, está organizado com base nessa tabela, iniciando pelas representações que colocam a criança como centro, depois avançando para as outras duas.

\subsubsection{Criança como centro}

Começamos por uma representação mais "renuncista", que considera que todos os esforços dos pais devem ser voltados para a criança. Essa foi a que se mostrou mais "populosa", de modo que precisamos a separar na sua associação em outras três crenças morais que as embasam.

\subsubsection{A sociedade como um todo é corrompida}

O primeiro comentário² a ser apreciado em nossa análise é o seguinte:

Espero que seja um mal entendido, pois seria hediondo usar o dinheiro arrecadado para luxos e futilidades. Mesmo que tenham passado o ano inteiro no hospital , agora não era hora de viajar e sim se concentrar na saúde do filho [...] Se for verdade o mal uso, quantas pessoas, criancas e etc seram prejudicadas daqui pra frente devido a desconfiança dos possiveis doadoes ? Isso é sórdido demais [SIC]

\footnotetext{
${ }^{2}$ Os comentários serão retratados exatamente como foram encontrados para manter a fidedignidade dos dados, a despeito de sua incorreção gramatical. As apontaremos com a expressão Sic.
} 
Podemos ressaltar as ideias de "luxos" e "futilidades", pois elas desviam o casal do foco na "saúde do filho", o que resulta no julgamento negativo. Além disso, podemos perceber o ideal da pureza sendo corrompido na sociedade em geral: como vai se confiar que ainda exista altruísmo se a confiança é traída envolvendo algo sagrado e puro como a criança? Esse temor se confirma, no mínimo, na seguinte fala: “É... Neste país não se pode confiar em ninguém, Não é só político que é safado, muita gente da população não vale nada [SIC]" (CARNEIRO, 2018, s/p). A palavra "população" situa o julgamento diretamente nos civis, parcialmente corrompidos em relação aos políticos (como veremos adiante). Essa concepção é reforçada em outra fala: "Nem solidário se pode ser mais nesse país! [SIC]" (G1 SC, 2018, s/p), ressaltando-se a palavra "país" para referir exatamente ao contexto nacional. Essa ideia fica explicitada em outro trecho: "Depois da Suzane Richitofen; não sobrou mais ética e moral neste país. Agora é ladeira abaixo!!!! [SIC]" (G1 SC, 2018, s/p). Esse último comentário aponta exatamente para o momento em que um valor passa de individual para coletivo, que se converte de patológico para normal e passa a ser esperado daquele momento em diante.

É nessa dinâmica que valores (como o da doação) ficam ressignificados:

\begin{abstract}
a doação é um ato voluntário........logicamente que as pessoas fazem de boa fé conforme a história se apresenta........, como nas Igrejas e templos........., o seu donativo é de boa fé, quem recebe nem sempre age da mesma maneira....ai vira caso de polícia.....é ela que deve investigar....se as pessoas desconfiam da boa fé daqueles....que procurem formular uma queixa........., não esqueçendo que o ônus da prova é de quem acusa.........Na verdade há tanta exploração da boa fé das pessoas......na cara dura.......basta ver os canais de TV, em busca de esperança e fé.........se enriqueçe muitos..........né não? [SIC] (CARNEIRO, 2018, s/p)
\end{abstract}

A "exploração" no tecido social brasileiro aparece descrita em detalhes e perpassa muitos níveis da vivência cotidiana. Isso, evidentemente, aponta para uma generalização. Porém, ainda há esperança na justiça, ponto que será mais desenvolvido no tópico seguinte. A última fala que condena completamente a sociedade de maneira total é esta: "Domingo visitei Embu das Artes e tinham dois rapazes dando risada no bar no centro. Quando fui embora e peguei o carro no estacionamento do outro lado do centro, um deles estava na porta fingindo paralisia e mudes [SIC]" (G1 SC, 2018, s/p). 
Um traço importante é que o bode "normal” parece agonizar, mas ainda resiste em alguns grupos. No caso, é o contexto regional (estadual) que ainda recebe alguma consideração, no qual podemos perceber o bode expiatório funcionando nas seguintes falas: “...vergonha para o povo Joinvillense [SIC]" (G1 SC, 2018, s/p), "Acompanhei como movimentou e comoveu a cidade!! Sem perdao... [SIC]" (G1 SC, 2018, s/p). Nessas falas, o casal é separado da região e o bode expiatório acontece normalmente para redimir o restante do grupo.

Da mesma maneira, ainda há indivíduos que acreditam em alguma retidão moral do povo brasileiro e que transformam os mesmos atores em bode em um segundo sentido: "SULISTAS, SEMPRE SERÃO e agirão como autênticos sulistas; depois do que fizeram com as terras que roubaram dos índios do Sul, fatos como este não deveriam surpreender ninguém, fato [SIC]" (G1 SC, 2018, s/p). O sul vira o bode expiatório para salvar o resto do país, e assim a criança segue intocada.

\subsubsection{Fé na justiça}

Nesse conjunto de falas a justiça é a palavra final, como aparece no seguinte trecho: “inaceitavel, lamentável.. tem lei para capar um sujeito desses? [SIC]” (BASSETE, 2018, s/p). Se em um primeiro momento a justiça é chamada a agir nesse momento, em outro a confiança na justiça ainda se expressa: "Se ficar demonstrado, são vagabundos da pior espécie, e a criança, tadinha, vítima também. Tem que vender todos esses bens, abrir uma conta e a justiça determinar um tutor pra administrar financeiramente o tratamento do garoto. O ser humano é um lixo [SIC]" (BASSETE, 2018, s/p). O encerramento com o "ser humano é um lixo" demonstra que há uma desesperança, porém, a justiça pode corrigir ao menos essa falha de ação, o que também é evidenciado por outra fala: “Agora podem ver... depois deste escândalo, a justiça deveria interditar a criança e nomear um C'urador/Tutor independente de qualquer pessoa da família [SIC]" (BASSETE, 2018, s/p). A palavra "deveria" serve para atribuir uma função a um agente, que deve, em primeiro lugar, afastar a criança da família para não permitir o seu "contágio" por ela. Isso é reforçado em outra fala: 
E digo mais, como ficou comprovado que pegaram o dinheiro, tira o filho do casal, da para pais que queiram, e que o tratamento seja pago, e em relação a mãe ficar livre, só tenho uma coisa a dizer, ela andava no carro não? ou vai dizer que não sabia da compra de um carro de 140 mil? e eu aqui andando de fusca, é muita falkatrua man, o pior que que quem realmente precisa fica prejudicado porque o povo desacredita por conta de um casal bandido desses [SIC] (G1 SC, 2018, s/p)

Ou seja, o casal não se preocupa com a "vida do garoto", o que vai de encontro com a concepção do comentador, que coaduna com a ideia de criança inocente. Outras falasvão propor soluções diretas, que necessitam de um veredicto de um juiz: "PRISAÕ DOMICILIAR ATÉ O MENINO FICAR BOM, SÓ SAI PRA LEVAR O MENINO NO MÉDICO E CASA, ASSIM APRENDE A SER HOMEM E MULHER ESSE É O RECADOS PROS PAIS. [SIC]” (G1 SC, 2018, $\mathrm{s} / \mathrm{p}$ ). Assim, a justiça pode ajudar os pais a cumprirem sua função, porém outras falas remetem a excluir os pais da vida do menino: “Esses merecem ficar presos... para sempre! [SIC]" (G1 SC, 2018, s/p).

Há análises também sobre a origem do comportamento do casal. Por exemplo, acerca da mentira: "Para que um carro de 140 mil? Tantos carros na faixa de 30 e 35 mil. Se falar que isso não é luxo está de brincadeira [SIC]" (G1 SC, 2018, s/p). Assim, a dádiva não foi retribuída em prol do luxo, mas existem ideias de que isso não é uma atitude de todo imprevisível: "Dinheiro na mão muda a opinião. A intenção era nobre, mas diante uma sociedade q idolatra o consumismo dá nisso [SIC]" (G1 SC, 2018, s/p). E também podemos arrolar a seguinte posição:

\footnotetext{
Em um país onde líderes políticos que roubam milhões do povo e de empresas estatais fazem "vaquinhas" para angariar fundos para fazer campanhas políticas e estes mesmos só viajam de jatinho pra cima e pra baixo fugindo do povo em vôo comercial, de nada admira estes sujeitos usarem a mesma prática para se darem bem com um propósito obscuro diante de tal situação do filho, pra eles está claro que a vida do garoto é o de menos, [...] [SIC] (CARNEIRO, 2018, s/p)
}

Podemos perceber, a partir da assunção dos pais com uma representação social de políticos, uma conexão do público com o privado. Não vamos investigar profundamente a figura do político, mas podemos levantar mais elementos relacionados a esse grupo que ajudem a explicar os próprios pais, como nas falas “ESSE SERVE PRA SER POLÍTICO, TIRA DOS OUTROS EM BENEFÍCIO PRÓPRIO [SIC]” (G1 SC, 2018, s/p) e “O método que eles usaram, é condizente com um certo condenado quando se aposentou por deficiência após 
perder o dedo minguinho [SIC]" (G1 SC, 2018, s/p). Nesses trechos, políticos no geral aparecem como efetivamente egoístas, e há explicitamente referência ao ex-presidente brasileiro Luís Inácio Lula da Silva, que acaba sendo o único político identificado diretamente nas falas que levantamos. Outra fala remete a uma ideia semelhante: "O uso do termo "Bebê Jonatas" já é a implantação da ideologia de gênero no inconsciente do povo. Afinal de contas, trata-se de um menino de 2 anos [SIC]" (G1 SC, 2018, s/p).

Por fim, há uma solução que considera a possibilidade de ingenuidade do casal:

Acho que o pensamento nem foi prejudicando o filho, pq devem ter imaginado $\mathrm{q}$ pelo ritmo das doações, iam passar do montante necessário. $O$ correto era pensar no repasse de $\$$ a outras famílias q possuem filhos na mesma situação e não esse pensamento egoísta de mamar no \$ q sobrasse... [SIC] (G1 SC, 2018, s/p)

Assim, enxerga-se a transgressão a partir do ângulo da ingenuidade perante uma sociedade que tem valores que contrastam com o do comentador. Porém, a solução encontrada não é a punição do casal, mas sim o repasse do dinheiro a quem possui os mesmos valores. É possível perceber aqui uma certa contradição, pois egoísmo e ingenuidade parecem se confundir na fala do autor, porque atribui ao casal conhecido a ingenuidade e ao casal em potencial o egoísmo. Dessa avaliação sobre o casal derivam posições que defendem sua perversidade.

\subsubsection{A suposta perversidade do casal}

A certo momento dos comentários, iniciam-se os ataques diretos ao casal, e não à sociedade em geral, que aparece de maneira indireta "fornecendo" matéria prima para um egoísmo. Começaremos pelo trecho: "Que bandido não tem caráter nenhum, isto todo mundo já sabe (mesmo que haja aqueles que querem justificar os seus malvados preferidos). Agora, aproveitar-se da deficiência da filha para ganhar e gastar dinheiro é de uma sem-vergonhice e baixeza sem medida [SIC]" (G1 SC, 2018, s/p).

Quanto aos doadores, a percepção deles também foi dividida. Por um lado são tratados como ingênuos: "Casal sem vergonha isso sim e mais trouxe é quem ainda doa dinheiro depois de desmascarar esses dois que já passaram até no fantástico [programa da rede de televisão Globo]... [SIC]" (G1 SC, 2018, s/p). Esse trecho refere à pessoas que ainda 
caem na alegada lábia do casal, cujas ações permitiram "se aproveitar de um anjinho doente pra $\mathrm{n}$ trabalhar e ganhar tudo de mão beijado, sinto por esta criança q tem esses pais pilantras [SIC]" (G1 SC, 2018, s/p). Porém, ainda há uma "absolvição" em outra fala: "Pra quem doou, pode ficar tranquilo, que o que é dado de bom coração com boas intenções, volta em dobro. Pra eles terão uma breve alegria material e padecerão eternamente em sofrimento [SIC]" (G1 SC, 2018, s/p). Assim, as expressões "volta em dobro" e "sofrimento" parecem apontar para um sentimento religioso, que não estabelece uma tentativa de acalmar os ânimos dos outros participantes da página, sem desconhecer o que considera como uma perversidade.

Outra fala que é interessante é a que afirma que "No caso, não foi indiciada, simplesmente pelo bem maior, o bebê. Apesar de todos os pesares, ela cuida do bebê [SIC] " (G1 SC, 2018, s/p). A palavra "pesares" remete ao que considera o ato ainda uma perversidade, mas que não desconsidera o bem central, o bebê. Mas as consequências da ação são bem evidentes: "Por causa desses dois idiotas inescrupulosos, a criança e outros necessitados sofrem pela descrença na honestidade!! [SIC]" (G1 SC, 2018, s/p). "Sinto pelas crianças que precisam, chegará um dia que ninguém mais vai ajudar! A culpa será da ganância desses pais, que aproveitam de pessoas de bem! O certo seria que essas doações chegassem de outra forma e não nas mãos desses aproveitadores [SIC] !" (G1 SC, 2018, s/p). Ou seja, as ilhas de pureza, que são as outras crianças, vão ser prejudicadas em manter suas purezas. A figura do monstro fica bem contextualizada na seguinte situação:

[...] Dão este tipo de respota evasiva só para tentar se livrar das grades.... Qual é o benefício direto ao menino a quantidade de ókúlos de sol ? E a moto que foi apreendida... Seria para colocar a criança em cima ?????? Que monstruosidade, os próprios pais se aproveitando do filho especial para benefício próprio. VERGONHA ! [SIC] (BASSETE, 2018, s/p)

A expressão "benefício próprio", portanto, indica o parâmetro para se conceituar um monstro, mas seria uma condição de monstruosidade voluntariamente assumida. Isso porque o monstro pode ser fruto de uma hipocrisia: "Garanto que esses pais bateram panela!!!!! [SIC]" (G1 SC, 2018, s/p), clara alusão aos grandes protestos a contecidos no ano de em 2016. 
Um traço interessante dessa representação - que centraliza a criança por conta de sua inocência a ser preservada a qualquer custo - é que ela é bastante consoante com a que dá suporte ao Estatuto da Criança e do Adolescente no parágrafo único do art. $4^{\circ}$ :

A garantia de prioridade compreende: a) primazia de receber proteção e socorro em quaisquer circunstâncias; b) precedência de atendimento nos serviços públicos ou de relevância pública; c) preferência na formulação e na execução das políticas sociais públicas; (BRASIL, 1990)

Nessa normativa, portanto, aparece bem forte a questão da proteção da criança e da sua primazia completa em qualquer situação. Poderíamos ir mais longe e encontrar referências parecidas, por exemplo, na cultura portuguesa, na "fazedora de anjos" do livro "O crime do Padre Amaro", de Eça de Queiroz, que "fabricava anjos" ao assassinar bebês indesejados. A pureza da criança seria tal que ela se converteria, diretamente, neste ser da religiosidade cristã.

\subsubsection{Criança como paralelo}

Outra representação lida mais com a questão da convivência entre o conforto e o cuidado com a criança, sem uma exclusão mútua entre essas dimensões. Assim, a centralidade não é completamente na criança, mas ela faz parte da equação. Uma das falas, por exemplo, argumenta que:

As doações foram dadas de livre e expontanea vontade pelas pessoas, se eles utilizaram o dinheiro para mudar de casa para uma maior para dar melhor qualidade de vida ao filho e compram um carro para uso da familia com o objetivo de trazer melhor qualidade de vida a criança. Não podem ser privados de um momento de lazer depois de todo o sofrimento que passaram com o nascimento do filho com problemas de saúde. Acho que mereciam sim um descanso e umas merecidas ferias [SIC] (BASSETE, 2018, s/p)

Assim, para além de se pensar a sobrevivência material do infante, às suas necessidades primárias foram cogitadas paralelamente às necessidades secundárias da família como um todo. Nesse caso, a doação aparece como o oposto do roubo e, assim, o que pode ter sido considerado como estelionato foi relido como um período de "férias" da situação difícil, o que só pode ser descoberto se há uma contextualização. A percepção se 
repete nesta outra fala: "Pra esse casal cuidar do bebê ,eles tem que estar com a cabeça boa. Não vejo nada de mais eles terem um mínimo de conforto com coisas básicas . Muito triste... [SIC]" (G1 SC, 2018, s/p). Ou seja, há a absolvição moral dos pais, de certa maneira, pois não houve crime ou má-fé. Situação oposta da fala seguinte e que parece admitir que houve crime, e que o bem-estar da criança vai ser colocado em paralelo inevitavelmente. Por isso, sugere que seja retirada a autonomia do casal por meio da ação da instituição de justiça: "cara, o dinheiro tem que ir para o hospital, o hospital banca o tratamento e pronto, o casal não vê um centavo, toda doação deveria ser assim [...] [SIC]” (G1 SC, 2018, s/p).

Por fim, a última consequência dessa representação desemboca na seguinte formulação de um dos comentadores:

\begin{abstract}
Somente os país sabem a dor que estão passando ... Eles pediram ajuda e, quem os ajudou fez por amor, eles não inventaram uma doença para angariar fundos,não roubaram , mas, pediram e receberam; quanto a viajem e os gastos eles procuram dar o melhor para a criancinha enquanto podem estar com ela pois ninguém sabe quanto tempo eles ainda terão para viver juntos.Se há alguém errado nessa história é a própria justiça que está os condenando indevidamente [SIC] (G1 SC, 2018, s/p)
\end{abstract}

Nesse caso, a doença poderia privar os pais da presença da criança e há certa compensação desse risco a partir do luxo material. A dádiva de cuidar do filho, assim, é correspondida pelo conforto material. Assim procedendo, a justiça está, nesse caso, privando os pais do contato com o filho, tornando a história mais dramática para o casal. Expostas essas ideias das duas primeiras representações, avançamos para a última delas.

\title{
2.2.3 Criança beneficiada pelo egoísmo dos pais
}

A última representação que estudaremos adere ao bem-estar individual. A particularidade metodológica dessa representação é que nela também alocamos informações mais irônicas, que parecem atacar as outras concepções morais através da ironia do que enunciar um julgamento direto.

O primeiro conjunto de falas coloca a responsabilidade da situação no estado: "Nada disso teria acontecido se nossa Saúde Pública fizesse sua parte direitinho [SIC]" (BASSETE, 2018, s/p). Assim, o desenrolar dos acontecimentos começou por essa falha 
primária, o que é repercutido em algumas falas que se remetem, também, aos políticos brasileiros: "Arrecadaram dinheiro para favorecimento proprio com o falso viés de ajudar alguem e foi preso??Acho que $99 \%$ dos politicos se encaixa nessa em dona juiza!!! [SIC] " (G1 SC, 2018, s/p). Outra fala afirma também que: "Ou seja, o dinheiro vai sair da mão de dois estelionatários para ir para nos bandidos do governo, então da na mesma [SIC] " (G1 SC, 2018, s/p). Ou seja: dos políticos esses comentadores não esperam atitudes boas, o que não acontece em situações de pais envolvendo os seus filhos.

Também houve alegorias a líderes religiosos neopentecostais: "Os pastores também arrecado doação usando a fé das pessoas para seu benefício próprio e a justiça não faz nada e a mesma coisa [SIC]" (G1 SC, 2018, s/p). "Com essa experiência toda, logo abrirão uma Igreja e virarão pastor [SIC]" (G1 SC, 2018, s/p). Nessas duas falas, podemos observar uma associação entre os pais aos políticos e a pastores. Esses depoimentos podem ser uma pista para indicar empiricamente que nem o sistema político e nem o pluralismo religioso estão gerando o sentimento de pertença em todos os públicos.

Em penúltimo lugar, também existiram comentários que alegaram que a centralidade da criança está sendo mantida mesmo com um ato egoísta dos pais:

O bebê tem doença incurável e vai morrer. O dinheiro arrecadado cumpre sua
função - a de aliviar a terrível dor destes pais que foram brindados pela natureza
com um filho sem cura (ou por Jesus, seja qual for sua crença/convicção). O casal
deve recorrer da decisão e lutar pelo que é seu, de direito. Doação é doação - fato.
Que deus abençoe este lindo casal e o ajude e ficar com todo o dinheiro arrecadado.
Amém
[SIC]

Em último lugar, podemos apreciar pensamentos ligados estritamente a um individualismo, como um traço favorável. Um deles foi mais voltado para a culpabilidade da situação - "É muito dinheiro. Ele muda o focu de qualquer pessoa. Com tanto dinheiro não se poderia esperar outra coisa [SIC]" (G1 SC, 2018, s/p) - e outro para o mero egoísmo ético - “CAROS AMIGOS, SE EU RECEBER UM DINHEIRO PRA MIM, SEJA DOADO, DADO, OU SEI LÁ O QUE, MAIS SE FOR PRA MIM, SERÁ MEU, E DE MAIS NINGUÉM, FAÇO O QUE EU QUISER [SIC]” (G1 SC, 2018, s/p). Disso se pode derivar que não há necessidade de se realizar a retribuição da dádiva e que os respondentes não deveriam indignar-se exatamente com esse tipo de atitude. 


\section{REAÇÃO JURÍDICA: PORQUE O ECA NÃO FOI APLICADO?}

Vimos parte da repercussão pública na seção anterior. A partir desse momento podemos apreciar a reação jurídica, documentada pela imprensa: "A Polícia Civil de Joinville, Norte catarinense, pediu a prisão de Renato Openkoski [...] e indiciou ele e a esposa por estelionato e apropriação de recurso de pessoa com deficiência" (G1 SC, 2018, s/p). Notemos, não foi acionado o Estatuto da Criança do Adolescente na referida matéria, apesar de o bebê ser beneficiado pelo mesmo por conta de sua faixa etária.

Isso sem dúvida não aconteceu por falta de norma relacionada a crianças com deficiência. As normativas levantadas no ECA sobre o assunto foram as seguintes, ressaltando seus respectivos artigos discriminados entre chaves:

\footnotetext{
[Artigo 11] § 10 A criança e o adolescente com deficiência serão atendidos, sem discriminação ou segregação, em suas necessidades gerais de saúde e específicas de habilitação e reabilitação [...] [Artigo 47] § $9^{\circ}$ Terão prioridade de tramitação os processos de adoção em que o adotando for criança ou adolescente com deficiência ou com doença crônica [...] [Artigo 54] III - atendimento educacional especializado aos portadores de deficiência, preferencialmente na rede regular de ensino [...] [Artigo 66] Ao adolescente portador de deficiência é assegurado trabalho protegido [...] [Artigo 70-a] Parágrafo único. As famílias com crianças e adolescentes com deficiência terão prioridade de atendimento nas ações e políticas públicas de prevenção e proteção [...] [Artigo 87] VII - campanhas de estímulo ao acolhimento sob forma de guarda de crianças e adolescentes afastados do convívio familiar e à adoção, especificamente inter-racial, de crianças maiores ou de adolescentes, com necessidades específicas de saúde ou com deficiências e de grupos de irmãos [...] [Artigo 197-C] § 10 É obrigatória a participação dos postulantes em programa oferecido pela Justiça da Infância e da Juventude, preferencialmente com apoio dos técnicos responsáveis pela execução da política municipal de garantia do direito à convivência familiar e dos grupos de apoio à adoção devidamente habilitados perante a Justiça da Infância e da Juventude, que inclua preparação psicológica, orientação e estímulo à adoção inter-racial, de crianças ou de adolescentes com deficiência, com doenças crônicas ou com necessidades específicas de saúde, e de grupos de irmãos [...] [Artigo 208] II - de atendimento educacional especializado aos portadores de deficiência (BRASIL, 1990, s/p)
}

Todos esses trechos relacionam a questão da prioridade aumentada da criança e do adolescente com deficiência em situações mais difíceis: sem dúvida a legislação remete a maus tratos ou à exploração do trabalho infantil. Porém, esse não parece ser o caso: mesmo que nenhuma das normativas se relacione diretamente à situação, ainda poderia se acionar os princípios mais gerais nos seus artigos $1^{\circ}$ e $3^{\circ}$ : “Art. $1^{\circ}$ Esta Lei dispõe sobre a 
proteção integral à criança e ao adolescente [...] Art. $3^{\circ} \mathrm{A}$ criança e o adolescente gozam de todos os direitos fundamentais inerentes à pessoa humana” (BRASIL, 1990, s/p). Nesse caso, não se pode afirmar, propriamente, que a criança estava desprotegida, ou ao menos não completamente: “A prisão dela não foi pedida porque ficou comprovado na investigação que a mãe realmente cuida do bebê. Isso não ficou comprovado na apuração em relação ao pai" (G1, SC, 2018, s/p). Ou seja, o ECA serviu para definir o indivíduo, porém ele não conseguiu enquadrar toda a situação.

Neste caso, nos pareceu que foi aplicado o princípio jurídico da equidade. Foi essa filosofia que permitiu a concatenação de normativas cujas leis não remetem diretamente ao ECA - confeccionado diretamente para esse "público-alvo", e que também inclui a questão da deficiência em suas percepções. Mas o que viria a ser a equidade? "Entra aqui o conceito de eqüidade como critério interpretativo, que permite adequar a norma ao caso concreto e chegar à solução justa" (NETO; DOS SANTOS, 2004, p.17).

Assim, temos um caso concreto para a Justiça, que é a suposta exploração de uma criança por parte dos pais, para o qual é necessário produzir a adequação da lei à circunstância não prevista para garantir o que o ECA descreveu como direito. É possível prosseguir a investigação considerando que essa circunstância é a doação. Se seguíssemos por esse caminho, nos caberia começar pela definição de doação onerosa, caracterizada como: “Aquela em que o doador impõe ao donatário uma incumbência ou dever” (NON, 2015, s/p).

O dever, no caso, seria aquele de zelar pelo bem da criança. Todavia, ao levarmos a definição ao pé da letra, notamos que não há um contrato explícito que obrigue essa contraparte, o que não permite a sua revogação, tal como descrito no seguinte artigo: “Art. 562. A doação onerosa pode ser revogada por inexecução do encargo, se o donatário incorrer em mora. Não havendo prazo para o cumprimento, o doador poderá notificar judicialmente o donatário [...]".

Não conseguimos encontrar um CNPJ da campanha, pois ela, aparentemente, foi realizada pelo Facebook, que maneja o dinheiro arrecadado segundo uma política própria: "Você receberá os pagamentos elegíveis da campanha sete dias depois do recebimento da doação [...] Os criadores de campanhas de arrecadação de fundos deverão vincular uma conta bancária válida para receber pagamentos" (FACEBOOK, s/d, s/p). Ou seja, está 
explicado porque a justiça congelou exatamente esta conta e gerou o questionamento do pai de Jonatas com relação a atitude, visto que a conta bancária é a particular que o usuário havia registrado.

Portanto, por esse lado não seria possível enquadrar o crime, e por essa razão partimos para o estudo do estelionato. Este é descrito no Artigo 171: “Obter, para si ou para outrem, vantagem ilícita, em prejuízo alheio, induzindo ou mantendo alguém em erro, mediante artifício, ardil, ou qualquer outro meio fraudulento" (BRASIL, 1988, s/p). Nesse caso, a vantagem ilícita apontada pela acusação estaria em desviar o dinheiro do tratamento do menino para uma causa alheia a ela, a aquisição de bens que não remetem diretamente ao mote da obtenção do recurso financeiro.

Esta acusação, por si só, talvez desse conta do caso, mas parece que houve uma vontade extra. Pois, além do artigo 171, foi também aludido na decisão o artigo 89, que afirma: "Apropriar-se de ou desviar bens, proventos, pensão, benefícios, remuneração ou qualquer outro rendimento de pessoa com deficiência" (BRASIL, 2015, s/p). Assim, a pessoa com deficiência também assume o papel de protegida pelo estado com relação ao seu bem, e essa lei acaba agindo como um agravante do primeiro artigo.

\section{REAÇÃO DA FAMÍLIA}

Neste item, vamos analisar as respostas da família ao furor público, que resultou na ação jurídica. Assim, observamos quais foram as alegadas intencionalidades do casal para explicar certas atitudes, que foram lidas como a motivação real para a ação. Assim, algumas declarações foram dadas por parte do casal, a qual vamos analisar:

\footnotetext{
Diante das injustas acusações e da difamação que estamos sofrendo na mídia, estamos psicologicamente abalados e contamos com o apoio de todos os amigos para seguir com forças para lutar pela saúde do nosso menino. Queremos assegurar a todos que nos ajudaram, aos quais moralmente devemos sim satisfação, que graças ao apoio de todos as primeiras doses da medicação do Jonatas já foram adquiridas e ministradas, e TODO o dinheiro tem sido revertido EXCLUSIVAMENTE para o tratamento e bem estar da criança, o que não se limita à medicação, mas diversas outras despesas têm sido arcadas com o valor arrecadado para garantir que o tratamento surta efeito, tal qual o acompanhamento médico constante, adaptação de espaços, dentre outras. Informamos ainda que as medidas judiciais cabíveis para reparar os danos que estamos sofrendo por essa perseguição midiática já estão sendo tomadas por nossa equipe de advogados.
} 
Contamos com as orações e o apoio de todos neste momento difícil. Renato Openkoski. Aline Openkoski (MARINHO, 2018, s/p) [grifos do original]

Nessa fala podemos perceber que os próprios acusados realizam a separação entre moral (a obrigação com aqueles que doaram os bens) e a justiça. Assim, para esclarecer sobre o ocorrido, fica estabelecido que os gastos não são quantificáveis apenas pelo valor do remédio - que aparece como o símbolo da doença - e a injustiça vai ser reparada pelo julgamento final. Assim, o casal alega que a situação se torna duas vezes mais dificultada: pela "perseguição" e pela doença do filho.

O assunto parece que ficou mais grave quando a polícia bloqueou os bens, o que também gerou uma resposta:

\footnotetext{
"Isso não pode acontecer. Jon precisa destes recursos para sobreviver. Todo o dinheiro arrecadado está sendo utilizado exclusivamente para o tratamento do meu filho. Não levamos vida de luxo às custas das doações. Vida de luxo para mim, é ver meu filho andando, correndo na praia, comendo sozinho, brincando com o irmãozinho [...] Estão querendo manchar a imagem tão bonita da campanha AME Jonatas que extrapolou as barreiras de Santa Catarina e ganhou o mundo", comenta o empresário [SIC] (PRADO, 2018, s/P).
}

O congelamento, portanto, implica no contrário do que os doadores almejavam e prejudica a sobrevivência da criança - ou seja, da pureza. Mas essa sanha punitiva detectada pelo empresário parece ter também quebrado com o princípio dos direitos individuais:

Ele disse que recebeu a notícia do congelamento das contas com muita surpresa. "A decisão da Justiça nos causa estranheza, porque trata-se de uma conta privada. Os recursos arrecadados não são dinheiro público. De qualquer forma estamos recorrendo da decisão. Jon precisa destes recursos para seu tratamento diário", explica Renato Openkosk (PRADO, 2018, s/p)

A conta bancária interferida pelo governo simboliza essa perseguição, quando o público oprime o privado. A Constituição, nessa declaração, simplesmente foi quebrada por conta de interesses individuais (baseados, segundo o pai da criança, na inveja pessoal). Foi do seu esforço individual que teria resultado a viagem para um ponto turístico famoso, que se constituiu na maior das polêmicas: 
A respeito da viagem a Fernando de Noronha, Renato argumenta que o passeio foi pago por um médico amigo da família, e que as despesas na cidade também foram custeadas com renda da empresa do casal. "Não utilizamos recursos da campanha nesta viagem. Isto tem que ficar bem claro. Um médico amigo nosso nos deu a viagem de presente. Jonatas não foi e nem será prejudicado, ele é, e sempre será nossa prioridade", esclarece. (PRADO, 2018, s/p)

Ou seja, o casal afirma que a prioridade é o menino e sua inocência é o centro de sua preocupação, o que exclui o uso do dinheiro para outros fins. Assim, o núcleo da doação continua sendo "público" (a proteção da vida) e não os interesses privados, o que não justifica a vontade coletiva de realizar a expiação. Essa afirmativa é corroborada pelo seguinte trecho:

\begin{abstract}
Segundo Renato, Jonatas tem uma despesa média mensal de $\mathrm{R} \$ 50$ mil. "Tudo é arcado pela campanha. São médicos, nutricionistas, fisioterapeutas, equipamentos e produtos de higiene e alimentação. Estamos fazendo de tudo para que, mesmo diante de suas limitações, Jon tenha uma vida confortável. Ele precisa de muitos cuidados. Só para se ter uma ideia, na semana passada, tivemos que comprar um equipamento utilizado para ajudá-lo a tossir, que custou R\$ 21 mil. Também compramos um carrinho especial para o Jon no valor de $\mathrm{R} \$ 40$ mil”, revela (PRADO, $2018, \mathrm{~s} / \mathrm{p})$
\end{abstract}

Ou seja, a dimensão pública, possibilitada a partir de doações, contribuiu com o recurso financeiro; aos pais, por seu turno, cabe o recurso subjetivo, que é o afetivo:

\begin{abstract}
O casal também publicou texto em que afirma ter se tornado alvo de perseguição. "Eu e minha esposa lutamos pela nossa família desde que nossos filhos nasceram, fizemos uma campanha para fazer o tratamento do nosso filho e estamos fazendo o seu tratamento. Ele é acompanhado pelos melhores profissionais, seus aparelhos são os melhores, damos muito amor, carinho, cuidamos da melhor maneira possível", diz o texto. "E o que algumas pessoas falam é da viagem de de três dias junto com um casal de amigos nossos. É difícil porque ficamos um ano dentro de um hospital lutando pela vida do nosso filho e isso não é enaltecido", completa (CARNEIRO, 2018, s/p)
\end{abstract}

Trata-se de uma alegação de uma seleção de fatos que montam uma narrativa que o casal considera mentirosa. Assim, a vivência em hospital justificaria uma suspensão dessa rotina fatigante a partir da viagem. Nesse momento o casal está reivindicando a sua humanidade de poder usufruir de prazeres materiais, uma vontade de não assumir o papel de mártires. Sobre o remédio, podemos corporificar nele o senso de urgência: 
A demora na solicitação da vacina, que desde que o início eles anunciaram que o pedido era urgente. "nós estamos esperando também... não somente a questão dos impostos, né, que nós estamos esperando a redução ou a isenção dos impostos, mas estamos esperando também o Jonatas ganhar alta, ele precisa estar no mínimo 40 dias sem nenhum antibiótico, sem nenhuma medicação (BALANÇO GERAL, 2018, s/p)

Ou seja, uma circunstância externa (que envolve o governo também, paradoxalmente) produziu a demora da importação. O remédio, efetivamente, demorou para chegar ao usuário mesmo com a necessidade gerada pela situação de urgência. Porém, ainda há um outro ponto que é mais forte, a questão da comprovação da doença: “Uma das principais dúvidas é na demora da solicitação da vacina, já que eles informaram que a situação é urgente [...] uma denúncia anônima foi feita no fórum de Santa Catarina [...] inclusive a ausência do exame genético que comprove a doença" (BALANÇO GERAL, 2018, s/p). Nesse caso, podemos perceber que a dúvida corrói completamente a credibilidade do casal até mesmo na existência da doença do filho, a base de toda a situação que se desenrolou.

\section{REFLEXÃO GERAL: A CRIANÇA E O DIREITO NA SOCIEDADE}

Os dados coletados na pesquisa foram cotejados entre si e deram origem ao quadro 1, que serve como fechamento para as reflexões no interior desse espaço. Após elencar os diferentes trechos, alocando-os em "acusações" e buscamos a justificativa correspondente:

Quadro 1: origem da acusação, acusação e justificativa

\begin{tabular}{|l|l|l|}
\hline Origem da acusação & \multicolumn{1}{|c|}{ Acusação } & \multicolumn{1}{c|}{ Justificativa } \\
\hline Oficiais/Direito & Apropriação Indébita & O dinheiro foi doado \\
\cline { 2 - 3 } & Desvio do dinheiro & $\begin{array}{l}\text { Todo o dinheiro arrecadado vai para o } \\
\text { tratamento (existem outros gastos) - R\$ } \\
50 \text { mil/mês }\end{array}$ \\
\cline { 2 - 3 } & Vida luxuosa & Vida de luxo é ver o menino brincando \\
\cline { 2 - 3 } & Outras acusações & $\begin{array}{l}\text { Inveja de quem quer manchar a imagem } \\
\text { da campanha }\end{array}$ \\
\cline { 2 - 3 } & Bloqueio da conta & Mas não é conta pública \\
\hline
\end{tabular}


Revista do Programa de Pós-Graduação em Educação da Unochapecó ISSN 1984-1566 (on-line) ISSN 1415-8175 (impressa)

\begin{tabular}{|l|l|l|}
\hline \multirow{1}{*}{} & Viagem a Fernando de Noronha & $\begin{array}{l}\text { O passeio foi pago por um médico } \\
\text { amigo da família, após um ano dentro } \\
\text { de um hospital }\end{array}$ \\
\cline { 2 - 3 } & Despesas em Fernando de Noronha & $\begin{array}{l}\text { As despesas na cidade também foram } \\
\text { custeadas com renda da empresa do } \\
\text { casal }\end{array}$ \\
\cline { 2 - 4 } & Demora da Vacina & $\begin{array}{l}\text { Imposto precisa diminuir, alta de } \\
\text { Jonatas do hospital }\end{array}$ \\
\cline { 2 - 3 } & Agir como político/pastor & Saúde do menino em primeiro lugar \\
\cline { 2 - 4 } & Consumismo & $\begin{array}{l}\text { Tudo presente ou pago por lucro da } \\
\text { empresa familiar. }\end{array}$ \\
\hline & $\begin{array}{l}\text { Prejudicar outras crianças que } \\
\text { realmente venham a precisar de } \\
\text { doação }\end{array}$ & - \\
\cline { 2 - 4 } & $\begin{array}{l}\text { Pais são intermediários da causa, mas } \\
\text { não se pode confiar neles }\end{array}$ & - \\
\hline & Dinheiro corrompeu os pais & - \\
\hline & Pais mereceriam ser presos & - \\
\hline & Pais não priorizar bem-estar do filho & - \\
\hline
\end{tabular}

Fonte: autoria própria (2019)

No quadro é possível observar acusações de origem no direito ou em fontes nãooficiais. Os primeiros possuíram resposta direta por parte do casal, através da imprensa, enquanto os segundos não foram respondidos publicamente - porém é possível reparar que as justificativas não-oficiais ajudaram na formulação das oficiais, pois há evidentemente pontos de convergência.

Podemos observar que o casal responde à justiça provavelmente por esta possuir uma coerção legal, e as respostas estão, basicamente, organizadas em duas vias: ou que as despesas foram realizadas com rendas alheias à campanha ou que os gastos são compensações pelas dificuldades com a doença do filho. De qualquer jeito, estamos presenciando uma situação em que existem, por um lado, acusações (lançadas sem a contextualização avançada do caso) contra justificativas (que teriam de ser comprovadas pela prestação de conta). Ou seja, se há diferença entre o moral e o legal, às vezes o moral acaba fazendo que os juristas se debrucem sobre diferentes leis para buscar a equidade. 
Por último, esse quadro ajuda a abastecer com empiria a teoria da democracia disjuntiva "já que a institucionalização da democracia política ampliou direitos políticos e sociais, mas não se traduziu na expansão dos direitos civis" (LIMA, 2015, p. 126). Assim, parece haver um permanente sentimento nas falas de que aconteça a impunidade da injustiça, seja por omissão ou seja por falta de alcance do aparelho estatal. A desconfiança fica totalmente expressa no nível de agressividade de algumas pessoas, ou na descrença na moral do brasileiro em geral.

\section{CONSIDERAÇÕES FINAIS}

Neste artigo abordamos a situação que envolve uma criança (o bebê Jonatas) com relação à campanha de arrecadação para o tratamento da sua doença crônica, a AME. Nisso contextualizamos o caso, estudamos parte da repercussão pública e depois analisamos a ação da justiça a partir da legislação. A nossa conclusão é de que o ECA ajudou a descrever o direito, porém foi a busca da equidade que conduziu à combinação de normativas, mas que isso aconteceu, ao menos cronologicamente, após a repercussão pública.

De um ponto de vista teórico, de noção inequívoca de expiação de uma sociedade, o bode expiatório se fragmentou nos diferentes grupos. Além da fragmentação, parece que há uma representação bem intensa: nela, a humanidade seria caracterizada como "apodrecida" (ou ao menos o Brasil), e os políticos seriam piores. Nisso, de redistributiva a doação se converte em uma maneira de tentar preservar a humanidade em constante decadência - um mecanismo de purificação, nesse caso. O estelionato, portanto, confirma a ideia de corrupção do mundo. Para quem o percebe, não se trata de um alento, mas é um conforto saber que se pode perceber a realidade como ela é. Assim, a humanidade é o seu próprio bode ou o bode se inverteu: ser solidário é que é explicado pela individualidade, pois o ambiente social não parece favorecer quem o é.

O estudo indica, na articulação desses dados, que, na verdade, quem está doando dinheiro deseja acrescentar um bebê puro para o mundo, que tenha tomado contato apenas com a solidariedade. A indignação, assim, não se dá mais pelo roubo do que pelos pais atrapalharem esse processo. Assim, existem ilhas de pureza no mar da devassidão: porém, essas ilhas são invadidas pela ganância e de sagradas elas se tornam profanas, e a 
humanidade se confirma como decadente. A justiça, na fala do direito, tentou resguardar essa pureza e buscou alguma combinação para enquadrar juridicamente o casal. Nesse caso, a justiça acaba cumprindo a função de institucionalizar o bode expiatório.

A partir dos dados desse estudo, nos pareceu que a doação possui o efeito simbólico de apagar o background da vida do receptor: nesse caso, ao aceitar a doação, os pais perdem a sua autonomia e devem prezar pela simples sobrevivência material. Então, sua vida deve ser ascética, sem luxos, tal como se fosse um puritano descrito por Weber em "A ética protestante e o espírito do capitalismo", ou o príncipe ideal para Maquiavel (MAQUIAVEL, 2010). Os pais, nesse caso, se não desejassem repercussão pública, deveriam ter vivido asceticamente ou ao menos não ter publicizado algum modo de vida mais caro de ser custeado.

\section{REFERÊNCIAS}

ABATTI, Gabriele. Campanha AME Jonatas: Justiça devolve carro apreendido à família. 2020. Jovem Pan Joinville. Disponível em: https://jpnewsjoinville.com.br/campanha-amejonatas-justica-devolve-carro-apreendido-a-familia/. Acesso em: 08/12/2020.

ALMOND, Gabriel; VERBA, Sidney. La cultura cívica: estudio sobre la participación política democrática en cinco naciones. Madri: Euroamerica, 1970.

ARANTES, Rogério Bastos. Direito e política: o Ministério Público e a defesa dos direitos coletivos. Revista brasileira de ciências sociais, São Paulo, v. 14, n. 39, p. 83-102, 1999.

BALANÇO GERAL. Caso Jonatas: denúncias questionam destino de dinheiro arrecadado. RICMAIS. 2018. Disponível em: https://ricmais.com.br/sc/programas/balanco-geraljoinville/caso-jonatas-denuncias-questionam-destino-de-dinheiro-arrecadado. Acesso em: 31. out.2018.

BASSETTE, Fernanda. Polícia apreende bens dos pais do bebê Jonatas. Veja. 2018. Disponível em: https://veja.abril.com.br/brasil/policia-apreende-bens-dos-pais-do-bebejonatas/. Acesso em: 31.out.2018.

BRASIL. Código Penal Brasileiro. Brasília: Planalto, 1988.

BRASIL. Lei N 8.069, de 13 de julho de 1990. Dispõe sobre o Estatuto da Criança e do Adolescente e dá outras providências. Ministério da Justiça: Brasília, 1990.

CARNEIRO, Eduardo. Justiça apura desvio e bloqueia dinheiro de campanha para bebê com doença rara em SC. UOL. 2018. https://noticias.uol.com.br/cotidiano/ultimas- 
Revista do Programa de Pós-Graduação em Educação da Unochapecó ISSN 1984-1566 (on-line) ISSN 1415-8175 (impressa)

noticias/2018/02/02/justica-apura-desvio-e-bloqueia-dinheiro-de-campanha-para-bebecom-doenca-rara-em-sc.htm. Acesso em: 31. out.2018.

DE ABREU, Angela Maria C. U. Comportamento pós-social: análise conceitual e variáveis correlatas. Arquivos Brasileiros de Psicologia, Rio de Janeiro, v. 35, n. 2, p. 153-169, 1983.

DUARTE, Clarice Seixas. A educação como um direito fundamental de natureza social. Educação \& Sociedade, v. 28, n. 100, p. 691-713, 2007.

DURKHEIM, Émile. A educação moral. Rio de Janeiro: Vozes, 2017.

FACEBOOK. Quando receberei os pagamentos da minha campanha de arrecadação de fundos? Sem data. Facebook. Disponível em: https://www.facebook.com/help/1348270451957092. Acesso em: 07.dez.2018

FLORÊNCIO, Gabriela. Justiça pede nova investigação contra pais responsáveis pela Campanha AME Jonatas. 2019. NSC. Disponível em: https://www.nsctotal.com.br/noticias/justica-pede-nova-investigacao-contra-paisresponsaveis-pela-campanha-ame-jonatas. Acesso em: 08.dez.2020.

GIRARD, René. A violência e o sagrado. São Paulo: Paz e Terra, UNESP, 1990.

G1 SC. Polícia de SC pede prisão de pai de bebê com doença rara e indicia casal por apropriação de recursos de deficiente. G1. 2018. Disponível em: https://g1.globo.com/sc/santa-catarina/noticia/2018/07/30/policia-de-sc-pede-prisao-de-paido-bebe-com-doenca-rara-e-indicia-casal-por-apropriacao-de-recursos-dedeficiente.ghtml. Acesso em: 31.out.2018.

LIMA, Renato Sérgio de; SINHORETTO, Jacqueline; BUENO, Samira. A gestão da vida e da segurança pública no Brasil. Sociedade e Estado, Brasília, v. 30, n. 1, p. 123-144, 2015.

LOPES, Ricardo Cortez; DE AGUIAR, Taylor Pedroso. O Julgamento moral através de uma perspectiva socioantropológica: uma problematização do caso Isabella Nardoni a partir do método webnográfico. Ciências Sociais e Religião, Porto Alegre, v.19, n. 26, 2017.

MAQUIAVEL, Nicolau. O Príncipe. São Paulo: Penguin, 2010.

MARINHO, Ana Clara. Justiça bloqueia bens de casal que fez campanha para arrecadar dinheiro para filho com doença rara e passou o réveillon em Fernando de Noronha. G1. 2018. Disponível em: http://g1.globo.com/pernambuco/blog/viver-noronha/post/justicabloqueia-bens-de-casal-que-fez-campanha-para-arrecadar-dinheiro-para-filho-comdoenca-rara-e-passou-o-reveillon-em-fernando-de-noronha.html . Acesso em: 31.out.2018.

MARTINS, Paulo Henrique. A sociologia de Marcel Mauss: dádiva, simbolismo e associação. Revista Crítica de Ciências Sociais, Coimbra, v.1, n. 73, p. 45-66, 2005. 
Revista do Programa de Pós-Graduação em Educação da Unochapecó ISSN 1984-1566 (on-line) ISSN 1415-8175 (impressa)

MOSCOVICl, Serge. Representações sociais: investigações em psicologia social. Petrópolis: Vozes, 2009.

NETO, Amaral; DOS SANTOS, Francisco. A eqüidade no Código Civil brasileiro. Revista CEJ, Brasília, v. 8, n. 25, p. 16-23, 2004.

NON, Amanda. Art. 538 CC - Doação. 2015. Entendeu Direito? Disponível em: https://amandanonn.wordpress.com/2013/04/02/art-538-cc-doacao/

PICHON-RIVIERE, Enrique. O processo grupal. São Paulo: Martins Fontes, 2005

PETRY, Almerindo. Noções básicas de sociologia: a epistemologia e o pensamento dos clássicos. Porto Alegre: Cirkula, 2014.

PRADO, Windson. A verdade sobre o caso Jonatas. OCP News. 2018. Disponível em: https://ocp.news/geral/a-verdade-sobre-o-caso-jonatas. Acesso em: 31/10/2018.

ROSATI, Massimo; WEISS, Raquel Andrade. Tradição e autenticidade em um mundo pósconvencional: uma leitura durkheimiana. Sociologias, Porto Alegre, v. 17, n. 39, p.110-162, maio/ago 2015.

SELL, Carlos E. Sociologia clássica: Marx, Durkheim e Weber. Petrópolis: Vozes, 2017.

STEINER, Philippe. A dádiva organizacional: dádiva à distância e circuitos de troca. Tempo Social, São Paulo, v. 29, n. 1, p. 23-43, 2017.

TEBET, Gabriela Guarnieri de Campos. Isto não é uma criança! Teorias e métodos para o estudo de bebês nas distintas abordagens da sociologia da infância de língua inglesa. Tese (Doutorado em Educação) - Programa de Pós-Graduação em Educação, Universidade Federal de São Carlos, São Carlos, 2013.

WEID, Olívia Von Der. Perdoe-me por te trair: um estudo antropológico sobre a infidelidade feminina. Habitus, Rio de Janeiro, v. 2, n. 1, p.49-59, 2004. 